\title{
Faculty of Health Sciences, Walter Sisulu University: Training Doctors from and for Rural South African Communities
}

\author{
Jehu E. Iputo, MBChB, PhD
}

\begin{abstract}
Introduction The South African health system has disturbing inequalities, namely few black doctors, a wide divide between urban and rural sectors, and also between private and public services. Most medical training programs in the country consider only applicants with higher-grade preparation in mathematics and physical science, while most secondary schools in black communities have limited capacity to teach these subjects and offer them at standard grade level. The Faculty of Health Sciences at Walter Sisulu University (WSU) was established in 1985 to help address these inequities and to produce physicians capable of providing quality health care in rural South African communities.

Intervention Access to the physician training program was broadened by admitting students who obtained at least Grade C $(60 \%)$ in mathematics and physical science at standard grade, and who demonstrated appropriate personal attributes. An innovative curriculum, combining problem-based learning with community-based education (PBL/CBE) in small tutorial group settings, was also adopted. This approach was aimed at educating and graduating a broader cohort of students, while training future doctors to identify, analyze, and treat health problems in the rural South African context.
\end{abstract}

Outcomes To date, 745 doctors ( $72 \%$ black Africans) have graduated from the program, and 511 students ( $83 \%$ black Africans) are currently enrolled. After the PBL/CBE curriculum was adopted, the attrition rate for black students dropped from $23 \%$ to $<10 \%$. The progression rate rose from $67 \%$ to $>80 \%$, and the proportion of students graduating within the minimum period rose from $55 \%$ to $>70 \%$. Many graduates are still completing internships or post-graduate training, but preliminary research shows that $36 \%$ percent of graduates practice in small towns and rural settings. Further research is underway to evaluate the impact of their training on health services in rural Eastern Cape Province and elsewhere in South Africa.

Conclusions The WSU program increased access to medical education for black students who lacked opportunities to take advanced math and science courses prior to enrolling in medical school. Innovative admission requirements and adoption of a PBL/CBE curriculum have made the WSU program one of the top training programs for black African doctors in South Africa.

Keywords: Problem-based learning, community-based education, rural health, medical training, healthcare workforce, human resources for health, South Africa

\section{INTRODUCTION}

Walter Sisulu University (WSU) is a multi-campus university located in Eastern Cape Province (including the former Transkei homeland), South Africa. WSU was established in 2005 when the University of Transkei (UNITRA) in Mthatha merged with two technical colleges, one in East London and one in Butterworth. The Faculty of Health Sciences was founded at UNITRA in 1985 with the objective of educating doctors with the knowledge, clinical skills and professional attitudes that would enable them to provide quality health care in rural Transkei communities. This mission continues to guide medical training at WSU today, where much of the region remains a rural, impoverished area with rampant unemployment, a high infant mortality rate, and a high prevalence of HIVIAIDS.

At its inception, the Faculty of Health Sciences adopted the traditional medical school curriculum, although this generated a lively debate among doctors, policy makers and medical educators within and outside the university - about whether the tertiary hospital-based, technologically-driven, Western-style curriculum would produce doctors who would be effective communicators, loyal team members, prudent managers of scarce resources, and providers of comprehensive primary care. Among various stakeholders, these were the basic attributes deemed essential for doctors working in the rural and impoverished environment of the Transkei. There was also consensus that in order for the new institution to fulfill its mission, an innovative pedagogical approach was needed.

A new curriculum, combining community-based education (CBE) with problem-based learning (PBL) in small groups, was adopted in 1992. With this approach, centered on the 'how' of medicine, teaching and learning are organized around community and patient health needs. Medical practice is likewise shaped by epidemiology and ecology, and is designed to alleviate the major health problems affecting the population by addressing demographic, socioeconomic, and cultural sources of ill health. Additionally, the Faculty adopted unconventional admission criteria intended to attract more black students and graduate more black doctors, especially from Transkei communities.

It must be recognized, however, that establishing a medical school in a South African homeland, using a new and untested curriculum, and run by a predominantly black faculty during the apartheid years in South Africa, was a daunting task. The proposal was met with skepticism from the white establishment, the medical profession, and the student body. Among many blacks, the idea at that time smacked of another attempt by the South African government to mount a substandard educational program for the black population. Advocates of the new model of training had to mount an intense program of consultation and education to win the support of the local community and the medical profession.

\section{INTERVENTION}

Increasing access through innovative admission criteria From the very beginning, an affirmative action plan was implemented in the medical training program aimed at increasing the number of black African students, especially from the Transkei region, and at achieving a student population whose racial profile would mirror that of the South African population (70\% black African; $20 \%$ white; $10 \%$ Asian and mixed races). In traditional South African medical schools, admission was based purely on aca- 
demic merit, but few black African applicants had the prerequisite higher grade matriculation passes in mathematics and physical science (equivalent to the British system Advanced Level School Certificate). Most secondary schools within the black population have limited capacity for teaching mathematics and physical science, and offer these subjects at standard grade (equivalent to the British System Ordinary Level School Certificate). The few black students who obtained higher grades in these subjects often chose to enroll in the old, established institutions rather than in the relatively new institution in a former homeland. To address the racial disparity among health care delivery personnel, it was imperative that admission of black students increase.

The university therefore adopted a policy whereby students who achieve at least Grade C (60\%) in mathematics and physical science at standard grade are considered for admission to the medical training program. In addition, the admission process looks beyond academic achievement and assesses the candidates' personal attributes as well. Applicants complete a biographical questionnaire, and candidates for admission are interviewed. The main attributes assessed are thinking skills, communication skills, interpersonal skills, and motivation.

\section{Designing a problem-based, community-oriented curriculum} From 1985 to 1991, medical training at the Faculty of Health Sciences followed a traditional curriculum. The Faculty was aware, however, that it was admitting students with a precarious academic background whose success in the program required reinforcement. Another critical issue in curriculum development was the need to provide students with the knowledge and skills to understand, research, and solve the health problems of rural South Africa. It is generally accepted that clinical competence is largely "problem (content) specific" and does not generalize well across different clinical problems.[1] Therefore, training a competent doctor with the technical and social skills needed to function in the healthcare delivery system in rural South Africa must include exposure to the common health problems in this community.

The medical educators developing curriculum in Transkei also hoped that early and prolonged exposure to rural community settings would increase students' commitment to serving those communities upon graduation. These concerns led to the adoption, in 1992, of a student-centered, problem-based, community-oriented and community-based curriculum that fosters active, life-long learning.[2-4]

\section{- Problem-based learning: The foundation}

WSU follows the classic problem-based learning model. The core of student activity is a group of eight to ten students plus one or two members of the teaching staff who act as facilitator-tutors. Each group meets for two-hour periods three times a week for ten weeks; then students are re-shuffled into new groups with new facilitators. During the first three years (the pre-clerkship phases), this tutorial process is based on set-piece clinical scenarios developed from real cases. The cases are formatted in a manner similar to the practice-based learning described by Barrows. [5] The problems used in these sessions are the priority health problems seen in rural South Africa, and all learning takes into consideration the family and community implications of the disease in question.
The first session begins with a brief statement regarding the patient's chief complaint. The students then discuss their hypotheses regarding possible diagnoses or disease mechanisms, as well as other questions they would like to ask the patient. More information is then provided based on available knowledge (the progressive disclosure method), and the same process is then applied to physical examination. Finally, the group uses the information gathered from the history and physical examination to determine which laboratory tests should be performed, and interpretation of the laboratory studies emerges from the discussion.

Because the WSU curriculum is based on the biopsychosocial model, the students analyze each case from a clinical perspective, a biomedical perspective, and a psychosocial perspective. With the tutors' help, students identify issues pertinent to the case from each of these three broad domains, study each issue, and report on what they learn in subsequent sessions. It is the tutors' duty to ensure that the issues selected are relevant to the case under examination. Nevertheless, responsibility for directing the learning process is shared between students and tutors. One feature of the tutorial process is adherence to the principal of student ownership of the process and the group's activities. The tutors are facilitators of the process rather than resource experts in any area under discussion. They serve to monitor and counsel on process matters and critical thinking, and are actively discouraged from answering questions of substance.

\section{- Community-oriented and community-based learning: Practice in context}

Given that the WSU Faculty of Health Sciences is a communitybased medical school, educational activities are not restricted to the teaching hospital. A significant proportion of hands-on professional training takes place in community settings under the tutelage of primary care physicians and other health care personnel. District hospitals, community health centers, clinics, private general practices, old-age homes, hospices, schools and community homes are used as part of the academic teaching platform and form the so-called "Academic Health Complex". This practice enables students to see patients in their own environment, where they also encounter problems not seen at tertiary hospitals. Students also learn how the health services function; the importance of teamwork and of involving the patient, family or community in health care issues; as well as the importance of health promotion and disease prevention.

WSU's commitment to community-based education is reflected in the extent of the Community-Based Education and Service (COBES) segment within the curriculum. During the 1st year, students spend two weeks getting introduced to the community and the local health care system. In the 2 nd year, students are sent to district hospitals for a period of three weeks, where they are also exposed to the community and community clinics. The 3rd year, students spend one day a week for the whole year in the community and community health centers. During this time, they learn clinical skills, identify problems, try to find solutions to prioritized problems, and learn how the community health center functions. Students culminate the year conducting a house-to-house diagnostic study. The purpose of this exercise is to put their theoretical epidemiological knowledge into practice while rendering a service to the community by collecting and analyzing environmental and health data, writing it up, and sharing it with all stakeholders for 
planning and for improving the health status of the community. The results of the study are shared at a major event held at the university bringing together community residents, university authorities, and the staffs of the community health center, district management, and the Faculty of Health Sciences. The information is also shared with provincial authorities.[6]

During the 4th year, students spend six weeks at district hospitals and surrounding clinics. At this stage, the emphasis is on primary health care problems both in and outside of the hospital. Students therefore see patients in wards, outpatient departments, emergency, surgery, peripheral clinics, etc. In the 5th year, students are again assigned to a primary health care setting for a period of six weeks, during which time they are exposed to patients at community health centers, hospices and old-age homes, and also complete a one-week general practice attachment.

\section{OUTCOMES}

Several studies have reported on the successful implementation of the PBL/CBE pedagogical model in terms of structure and function, [7-9] but few systematic, integrated analyses have been conducted to determine how graduates of the program are faring and how they are affecting the larger society. However, a few patterns are beginning to emerge.

Has WSU's innovative medical training program increased access to medical education for black African students who lack higher grade mathematics and physical science coursework? Currently, 511 students are enrolled in the physician training program at WSU: 430 (83\%) black Africans; 68 (14\%) Asian descendants; $8(2 \%)$ mixed race; and $5(1 \%)$ whites. Most of the black Africans enrolling in the program lack higher grade courses in mathematics and science (Figure 1).

Has admission of students with standard grade math and science preparation compromised their achievement as medical students and as practicing doctors? Evidence indicates that

Figure 1: Medical Student Intake, Faculty of Health Sciences, Walter Sisulu University, 1995-2005

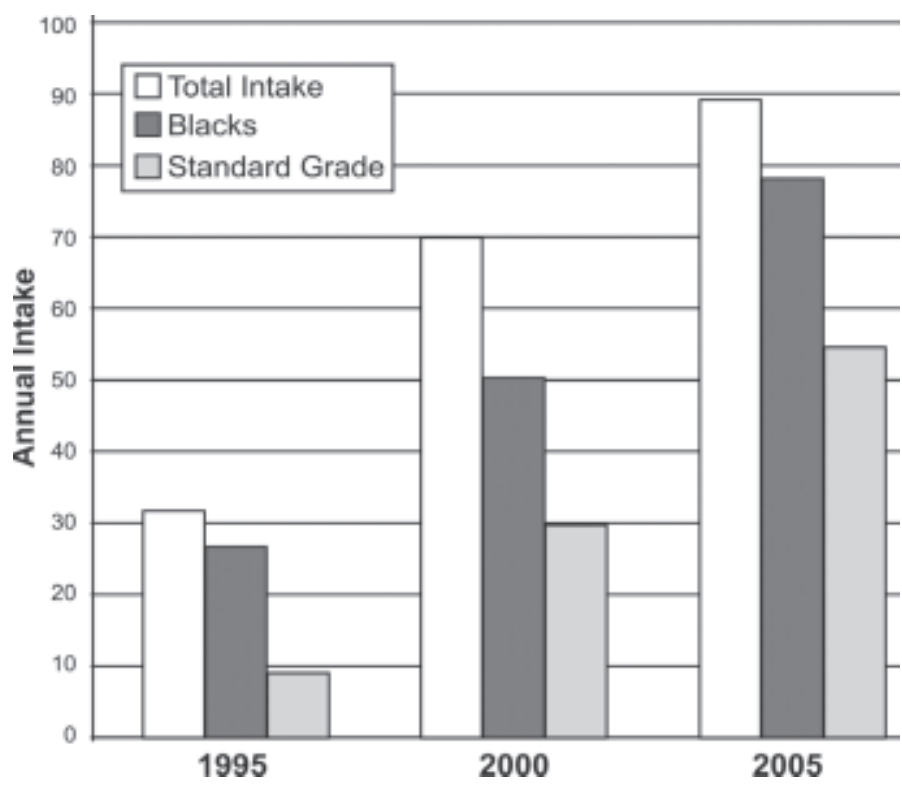

WSU students are coping well with the demands of the course. The attrition rate (percentage of the students who drop out) of black African students has been consistently $<10 \%$ for the past 10 years, compared to $>20 \%$ in traditional medical training programs in the rest of South Africa. The progression rate (percentage of students who progress from one level to another in a given year) of black African students has consistently been $>80 \%$.[10] WSU has graduated 745 doctors ( 111 from the initial traditional curriculum and 634 from the PBL/CBE curriculum). Of these graduates, $534(72 \%)$ are black Africans, 194 (26\%) are Asian descendants, $11(1.5 \%)$ are of mixed race, and 6 $(0.8 \%)$ are whites. These figures compare favorably with those obtained in other South African medical training programs, and more so when comparing the performance of the black African students.[11]

Does the WSU program foster the development of professional attitudes in the graduates? There has been no systematic study of this aspect; however, limited evidence to date indicates that WSU graduates are well prepared for medical practice. Upon entry to, and exit from, the program, students complete a semistructured questionnaire on their intentions to specialize or not, preferred place of work, and overall view of the future. The majority of students $(78 \%)$ are consistently found to be optimistic about the future, and most of them (90\%) wish to practice clinical medicine.[12] A review of cases brought before the disciplinary board of the Health Professions Council of South Africa over the past 10 years reveals a paucity of WSU graduates (6 cases). It is therefore reasonable to assume that the WSU training program inculcates appropriate professional attitudes.

Does the WSU program prepare students for success in postgraduate medical education? The WSU program is relatively young, and most of the graduates are still within the internship and community service phase of their clinical practice. However, 35 graduates from the initial traditional curriculum (32\%) and 79 graduates from the PBL/CBE curriculum (24\%) have either graduated from, or are registered with, a post-graduate training program, and it is encouraging to note that more than $50 \%$ of them have chosen the primary care discipline of Family Medicine.[13] Other popular disciplines are pediatrics, internal medicine, and obstetrics and gynecology. It would therefore seem that the WSU program fosters career choices in the primary care medical specialties.

Has the WSU program encouraged its graduates to work in public institutions or establish practice settings in underserved areas? Systematic research has been instituted to answer this question, which is of major concern to the university, since it deals with one of the major outcomes of the innovative curriculum. Preliminary data show that $36 \%$ of WSU graduates work in rural areas, $53 \%$ in urban settings, and $4 \%$ have either died or migrated overseas.[13] Those working in urban areas include graduates still in their internship years who are placed there involuntarily, as well as others engaged in postgraduate training in tertiary and academic hospitals found only in urban areas. Most graduates with established practices in urban areas are located in underprivileged townships. WSU graduates are more likely to choose to work in South Africa, as opposed to choosing to leave the country and work overseas, than graduates of any other South African medical school.[14] 


\section{DISCUSSION}

The small group tutorial process:

Challenge for teachers, key to student success

Increased access with success for black African medical students at WSU is mainly due to the student-centered training program. Initially, however, the small group tutorial, using a hypothetic-deductive format with progressive disclosure of problems, was a completely new approach to learning for both students and teachers. Experts in PBL - both local and invited from other institutions - conducted regular training sessions to help teachers make the transition from lecturer to tutor and facilitator of the learning process. Teachers have adjusted well to the new method, although there has been a tendency to relapse into lecturing mode, making continued tutor training necessary at least once a year. Specific areas of difficulty for teachers have been integrating psychosocial issues into the tutorial process, minimizing teaching in the tutorial room, and giving feedback to individual students in the tutorial - especially if the feedback is negative.[15]

Students, however, adapted to the small group tutorial process with relative ease. The program has had a significant influence on their learning styles, making them more comprehensive and versatile learners.[16] The small group tutorial process is inherently developmental. Students who entered the program with standard grade math and science initially struggled with the course content. But as they advanced, their performance improved and, by the third year, was on par with the rest of the students (Figure 2).

The PBL/CBE curriculum, especially the small group tutorial, has given more black African students access to medical training without the need for special extended programs, such as those required by some South African medical schools. Traditional medical training programs in South Africa take six years. Black African students admitted to these programs used to be placed in so-called developmental programs that lasted at least seven years. With PBL/CBE, WSU has been able to cut the duration of the program for all students to five years.

Figure 2: Performance of Higher Grade and Standard Grade Matriculants, Faculty of Health Sciences, Walter Sisulu University, 1992 - 2001

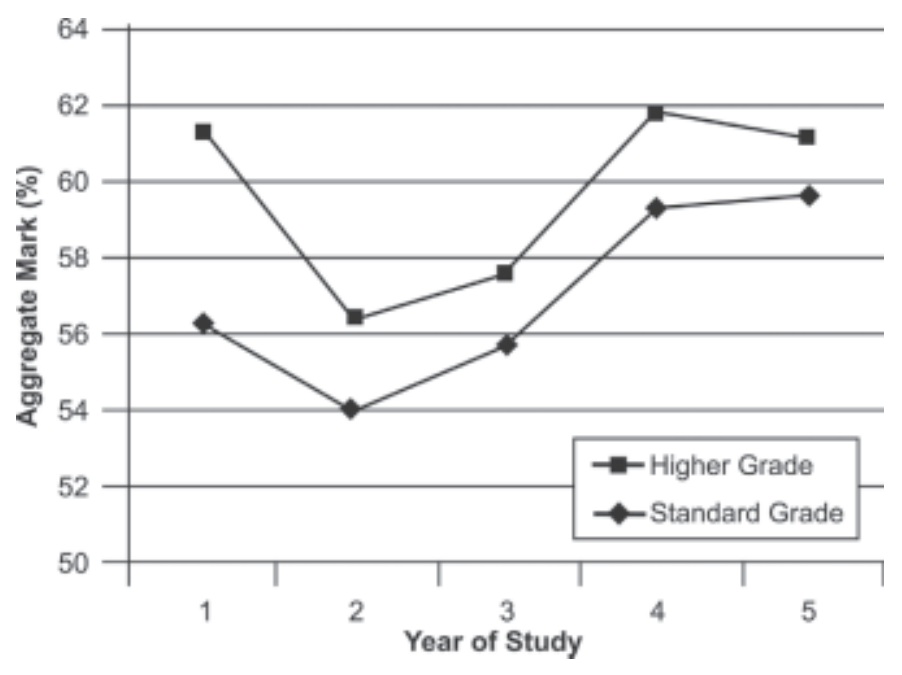

\section{The importance of international collaboration}

Converting the traditionally trained teaching staff to $\mathrm{PBL}$ pedagogy was an enormous task that would have not have succeeded without the help of colleagues from Bowman Gray School of Medicine at Wake Forest University, University of New Mexico and University of New Castle in Australia. These institutions had well-established PBL programs and gave some Faculty of Health Sciences staff practical exposure to running such a program. They also participated in training Faculty of Health Sciences staff on the small group tutorial process over a prolonged period of time. University of New Castle in particular should be credited with the establishment of PBL in the clinical years of the medical training program. Professor Gwendolyn Camp (Professor Emeritus in Medical Education, University of Texas, Medical Branch, Galveston) mentored a number of Faculty of Health Sciences teaching staff who played a leading role in the successful implementation of the program. The Education Commission for Foreign Medical Graduates has over the years provided Faculty of Health Sciences staff with fellowships that have enabled them to travel to the United States for seminars, training sessions and general exposure to the best practices in medical education.

An initial challenge to the community-based aspect of the training program was gaining entry to the rural communities where faculty and students would be teaching and learning, and the same time involved in community service and development activities. The Kellogg Foundation came to the rescue and offered funding to establish the University Community Health Partnership Projects, which enabled the UNITRA to establish six academic health centers in rural areas. Over the years, these health centers have become pivotal centers of community-based education and service.

Recruiting the appropriate teaching staff has also been a major problem because of Mthatha's geographical location. Medical staff is reluctant to relocate to a rural area with limited social amenities. In 1997, the post-apartheid South African government approached the Cuban government about supporting the medical training program in the Eastern Cape with teaching staff. Cuba was an appropriate source of PBL/CBE teaching staff, since their medical education programs also place great emphasis on community-based training. The PBL/CBE program started with an initial cohort of 30 students. With the help of Cuban teachers, intake has been scaled up to 100 students. The WSU program is an example of South-to-South cooperation in the training of human resources for health care delivery.

\section{Challenges to growth and sustainability}

The shortage of qualified teaching staff and the difficulty of attracting South African academics to work in Mthatha have been major obstacles to scaling up the program. More than $60 \%$ of the current teaching staff are not South African, and the program is still reliant on the Cuban teachers. The Health Professions Council, which sets standards for health professions training in South Africa, capped yearly intake into the training program at 100 students, based on the size of the teaching staff. There are currently 101 faculty members employed by the university: 19 Professors, 15 Associate Professors, 23 Senior Lecturers, 20 Lecturers, 8 Junior Lecturers and 16 Technical Staff. These are supplemented by 81 government employees who are Attending Staff at the Nelson Mandela Academic Hospital, the main teaching hospital for the training program. They include 6 Chief Specialists, 21 Principal Specialists, 12 Senior Specialists and 37 Specialists. 
There is a concerted effort to expand the teaching platform to include the two other tertiary hospitals in the Eastern Cape, the East London Hospital Complex and the Port Elizabeth Hospital Complex. Both are located in urban areas and would add significant skills and resources to the WSU program, including 116 staff members with specialties like anesthesia, otolaryngology, orthopedics, and cardiothoracic surgery, for which there is a severe shortage in the current teaching staff. Expansion to these sites, however, is being hindered by lack of teaching space and student accommodation. There is also concern that the PBL/CBE philosophy should not be compromised in the process of scaling up the program.

Full implementation of the community-based education and service concept to include service learning in the communities has yet to be fully realized. The Faculty plans to strengthen the Community-based Education and Service (COBES) component of the program by building learning centers in at least 10 district hospitals and by developing the concept of wellness village as a vehicle for service learning in the communities. However, dwindling funding and rising transportation costs - especially for community-based education activities - will continue to be major challenges to completion of these projects.

\section{Impact on health services}

The influence of WSU medical training on retention of graduates in underserved areas is still unclear. Long-term research is underway to obtain firm data on the number of WSU graduates practicing in private versus public service, as well as data comparing practicing WSU graduates to practicing graduates of other South African medical schools. More studies are needed to ascertain the demographic factors (e.g. gender, age, prior experience, family background, personality type, etc.) that are most likely to lead WSU graduates to choose work in private practice or in public institutions serving the poor sectors of society, as well as any relationship between the students' experi- ence in the community during training and the location of his/her practice upon graduation.

\section{Future perspectives}

The Faculty of Health Sciences' immediate plans for the future are centered on staffing issues, academic programs, and communitybased education. Expanding our tertiary teaching platform to include the East London and Port Elizabeth hospital complexes is a priority. The Faculty is also in the process of implementing a focused staff development program to identify, train, and nurture its graduates. Future plans include a Center for Health Professions Education Research and Training that will focus on PBL/CBE pedagogy, curriculum evaluation and strategic planning, and will be open to other institutions in Africa.

The Faculty has commissioned a modern hospital complex in Mthatha and also intends to expand the Biomedical Sciences training program - a potential source of teachers and researchers for the Faculty - as well as training programs for middle cadre health professionals. Optometry, Occupational Therapy, Speech and Language Therapy, Nutrition and Dietetics are some of the disciplines that are almost non-existent in this part of South Africa, yet are essential for the prevention and rehabilitation aspects of primary health care.

\section{CONCLUSIONS}

The Faculty of Health Sciences at Walter Sisulu University has established a strong training program in medicine and has opened up access to health professions training. It has established a network of district hospitals and health centers that are used as teaching platforms for the community-based curricula. This network also offers a springboard for involvement in community service and development activities. The Faculty of Health Sciences is recognized by the World Health Organization as a leader in the field of Problem-based Learning and Communitybased Education, and also serves as a resource for other medical training programs in Africa. -1 -

\section{REFERENCES}

1. Norman GR, Schmidt HG. The Psychological Basis of Problem-Based Learning - A Review of the Evidence. Acad Med. 1992;67(9):557-65.

2. Iputo JE Nganwa-Bagumah $A B$. The innovative medical curriculum of the University of Transke Medical School. Part I. Problem-based learning. S Afr Med J. 1996 Jun;86(6):649-51.

3. Iputo JE, Nganwa-Bagumah AB. The innovative medical curriculum of the University of Transke Medical School. Part II. Community-based learning. S Afr Med J. 1996 Jun;86(6):651-2.

4. Buga GA. Problem-based learning in clinical clerkship - the experience at the University of Transkei Medical School. S Afr Med J. 1998 Nov;88(11):1414-8.

5. Barrows HS, Tamblyn RN. Problem-based learning: An approach to medical education. New York: Springer; 1980

6. Del Rio A. Community Health Diagnosis as a Curriculum Component: Experience of the Faculty of Health Sciences, Walter Sisulu University, Eastern Cape, South Africa. MEDICC Review. 2005; VII(8):22-5

7. Nazareth I, Mfenyana K. Medical education in the community: the UNITRA experience. Med Educ. 1999 Oct;33(10):722-4
8. Mazwai EL. Training surgically competent doctors for South African rural settings. S Afr J Surg 1997 Aug;35(3):147-8.

9. Kwizera EN, Dambisya YM, Aguirre JH. Does tutor subject-matter expertise influence student achievement in the problem-based learning curriculum at UNITRA Medical School? S Afr Med J. 2001 Jun;91(6):514-6.

10. Iputo JE, Kwizera EN. The PBL/CBE curriculum reduces the attrition rate and improves the graduation rate of medical students. Med Educ. 2005 Apr;39: 388-93

11. Burch VC, Skikana CNT, Yeld N, Seggie JL, Schmidt HG. Performance of academically atrisk medical students in a problem-based learning program. Advances in Health Sciences Education. 2007 Aug:12(3): 1573-1677.

12. Dambisya Y. Career intentions of UNITRA medical students and their perceptions about the future. Educ Health (Abingdon). 2003 Nov;16(3):28697.

13. Igumbor EU, Kwizera EN. The positive impact of rural medical schools on rural choices. Rural and Remote Health. 2005:5:417.

14. Reid, S. Community Service for Health Professionals. South African Health Review. 2002:145-6.
15. Iputo JE. Facilitating the integrated small-group tutorial in a medical program - the University of Transkei (UNITRA) experience. S Afr Med J. 2005 Dec;95(12):959-62.

16. Iputo JE. Impact of the problem-based learning curriculum on the learning styles and strategies of medical students at the University of Transkei. S Afr Med J. 1999 May;89(5):550-4.

\section{THE AUTHOR}

Jehu E Iputo (Corresponding Author: iputo@worldonline.co.za), chair of the physiology and biochemistry departments at the Walter Sisulu University Faculty of Health Sciences, Eastern Cape Province, South Africa.

Submitted: May 1, 2008

Approved for publication: September 1, 2008 